\title{
Performance Characteristics and Evaluation of Alternate Materials for Automobile Advanced Leaf Springs
}

\author{
Stephen.A.Takim. \\ Department of Mechanical Engineering Cross River University of Technology, Calabar, Nigeria.
}

\begin{abstract}
Leaf springs are crucial suspension elements in automobile, necessary to minimize the vertical vibrations, impacts and bumps due to road irregularities. The functions of the suspension springs for an automobile are to maintain a good control stability and to improve riding comfort. In other to meet the requirements of natural resource conservation and energy economy, automobile manufacturers have been attempting to reduce the weight of vehicles in recent years. The research reviewed the automotive leaf spring in it entirety as well as the used of CES EduPack 2011 software to justify the conventional material used for leaf spring.

The paper also analyse an indebt configuration and methodologies that enable the researcher to select an alternate and advanced composite material suitable for leaf spring using the Cambridge Educational Software (CES) in other to meet the global glamour for automotive weight reduction, conservation of natural resources and energy minimization as been focus by automobile manufacturers in the present state.
\end{abstract}

Key words: Leaf springs, Alternate materials, Automobile.

\section{Introduction:}

The use of leaf spring can be trace back to the year 1804 when the inventor "Obediah Elliot" first used the leaf spring on horse- drawn and later on railway rolling stock (Nunney, 2007). Early designers of motor vehicle then took the advantage of this spring because it has the capacity of varying the leaves easier as well as obtaining the desired degree of resilience by varying the width and thickness of the leaves.

Venkatesan and Helmen (2012) maintained that leaf springs also known as flat spring are made out of flat plates. Leaf springs are designed in two ways: multi-leaf and mono-leaf. The leaf springs may carry loads, brake torque, driving torque, etc... In addition to shocks. The multi-leaf spring is made of several steel plates of different lengths stacked together. The material used for leaf springs is usually a plain carbon steel having 0.90 to $1.0 \%$ carbon. For automobiles: $50 \mathrm{Cr} \mathrm{1,50} \mathrm{Cr} 1 \mathrm{~V} \mathrm{23}$, and $55 \mathrm{Si} 2 \mathrm{Mn} 90$ all used in hardened and tempered state. For rail road springs: C 55 (water - hardened), C 75 (oil-hardened), 40 Si 2 Mn 90 (water-hardened) and 55 Si 2 M N90 (oil-hardened) (M.venkatesan., D.helmen devaraj, 2012).

There are generally classified into three basic types to include,

- Multiple-leaf spring

- Mono-leaf spring and

- Fibre composite spring

\section{Section 1:}

1.1: Review of how leaf spring functions as part of the system:

Majority of the leaf spring function on dual capacity, one as a load carrying member and second as an axel control member. The spring is bolted tightly to the frame of the vehicle through the thick end, while the free end is attach to the axel through a bushing. Most of the trucks and light vehicles are equipped with leaf springs as shown figure1 (a), either in the front or rear axle suspension systems in order to improve the ride comfort and to support heavy loads.

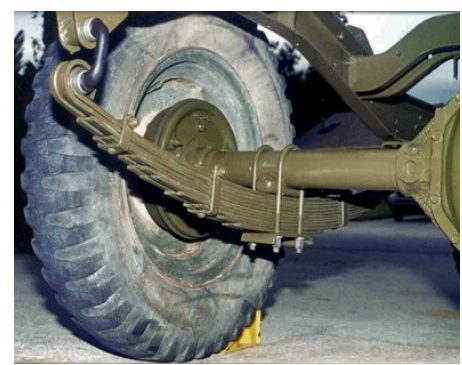

Figure 1(a): Shows a truck equipped with leaf spring. 
They are interposed between the wheels and the body so that the body is partially isolated from the axle. This permit the axel can move autonomously from the body.

"When a vehicle rides over rough grounds, the wheels will rise when rolling over bump and will deflect the springs. The energy created due to this movement is momentarily stored in the spring; it is then release again, due to the elasticity of the spring material, and in expending this energy the spring will rebound. The spring will then oscillate at its natural frequency, causing the vehicle to bounce many times before equilibrium is restored" (Heisler, 1999). If the body were firmly joined to the axel, the kinetic energy produced by the bump would be imparted directly to the body, creating high impact stresses to the chassis and panelling and discomfort to the passengers.

Tomas W. Birch (1999), observed that as the spring absorbs load and deflects, the leaves change from a curve shape to a flat shape and then re-curve in the order direction. The length of the leaves is also change considerably as they flatten out and bend. However to take care of this changes most leaf springs uses shackle; while also there is a certain amount of sliding of the ends of one leaf over the next leaf, often know as interleaf friction.

Shiva Shanka and Vijayarangan (2006) also maintained that leaf springs are designed to absorb and store energy and then release it. Hence, the strain energy of the material becomes a major factor in designing the springs. The relationship of the specific strain energy (U) can be expressed as;

$\mathrm{U}=\boldsymbol{\sigma}^{2} /_{\mathbf{\rho}} \mathrm{E}$

Where:

$\boldsymbol{\sigma}=$ the strength,

$\boldsymbol{\rho}=$ the density and

$\mathbf{E}=$ the Young's modulus of the spring material.

It can be easily observed that material having lower modulus and density will have a greater specific strain energy capacity. Figure 1(b) shows the picture nature of leaf springs used either in the front or rear axle suspension systems in order to improve the ride comfort and to support heavy loads.

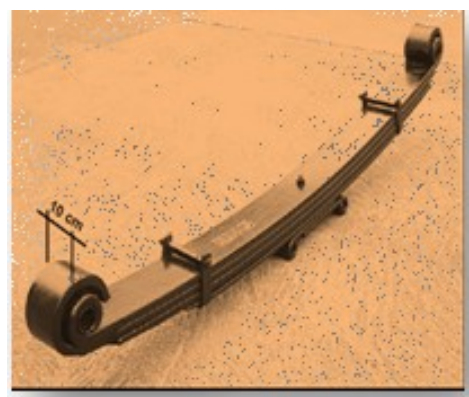

Figure 1(b): ature of leaf spring used either in front or rear axel

Source: J.J. Fuentes et al. Engineering Failure Analysis 16 (2009) 648-655]

\section{2: In-service condition, loading mode and material characteristics needed for leaf spring:}

The Goodman criterion may be used in the design of leaf spring subject to cyclic loading. This criterion is usually represented graphically as shown in figure 1(c) by plotting the mean stress that the component is subjected to $\left(\mathrm{Sigma}_{\mathrm{m}}\right)$ along the horizontal axis and the alternating stress amplitude, Sigma axis.

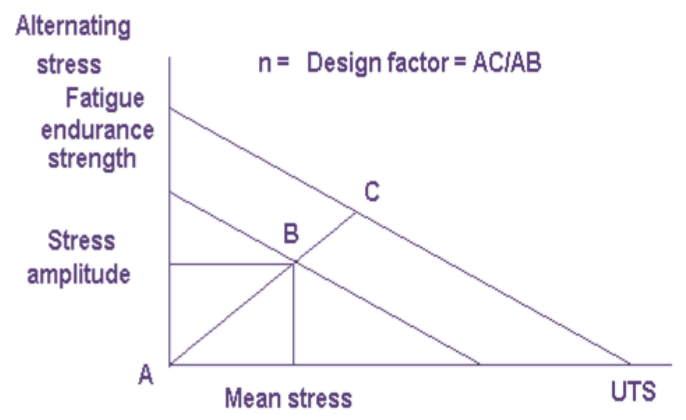

Figure 1(c) Fatigue diagram showing Goodman line. 
The UTS of the material $\left(\mathrm{S}_{\mathrm{u}}\right)$ is marked on the horizontal axis and the fatigue endurance strength, $\mathrm{S}_{\mathrm{e}}$, is marked on the vertical axis and the Goodman line connects these two points.

If the stresses on a safe design are marked as a point, B, on the diagram and a line drawn through this point and parallel to the Goodman line, the distance this line is away from the Goodman line is a measure of the factor of safety, or the design factor, $n$, of this particular part. [www.tech.plymouth.ac.uk/sme/desnotes/fatiguecalc.htm]

The leaf spring flexes through thousand of compression and expansion cycles without breaking and still retains their original shape (Birch, 999). However it is a well known fact that the common cause of spring failure is sag- a gradual reshaping of the spring that lowers the car.

Newton et al (1996), argued that leaf spring generally have an approximately only a quarter of energy storage capacity, for a given stress level, of either coil or torsion-bar springs. "The rate or the load rate of a spring is the change of load per unit deflection, and it varies along the length of the leaf. Under the application of load, the stress in the beam is zero along the neutral axis at it centre, and is maximum at the mid-point of the beam surface. The static deflection is the static load divided by the static load rate. In most cases, static deflection differs from the actual deflection of the spring between zero loads and static load due to the influences" (Mukhopadhyay et al 1997). Generally springs are subjected to a constant mean stress, and often experience variable stresses superimposed on a constant stress.

Hiroyuki Sugiyama et al (2006) however, argued that the suspension characteristic of leaf springs are highly nonlinear due to contact between spring leaves and hysteresis due to frictional effect. Furthermore, the windup motion of leaf springs leads to undesirable changes in caster angles and sometimes generates undesirable lateral movements that affect the lateral stability of the vehicles during braking or curved road negotiations.

Shiva Shanka and Vijayarangan (2006), also maintained that every automobile, i.e. four wheelers and railways, the leaf spring is one of the main components and it provides a good suspension and it plays a vital role in automobile application. It carries lateral loads, brake torque, driving torque in addition to shock absorbing. The advantage of leaf spring over helical spring is that the ends of the spring may be guided along a definite path as it deflects to act as a structural member in addition to energy absorbing device. The geometry of the Steel leaf spring is shown in Fig.1 (d)

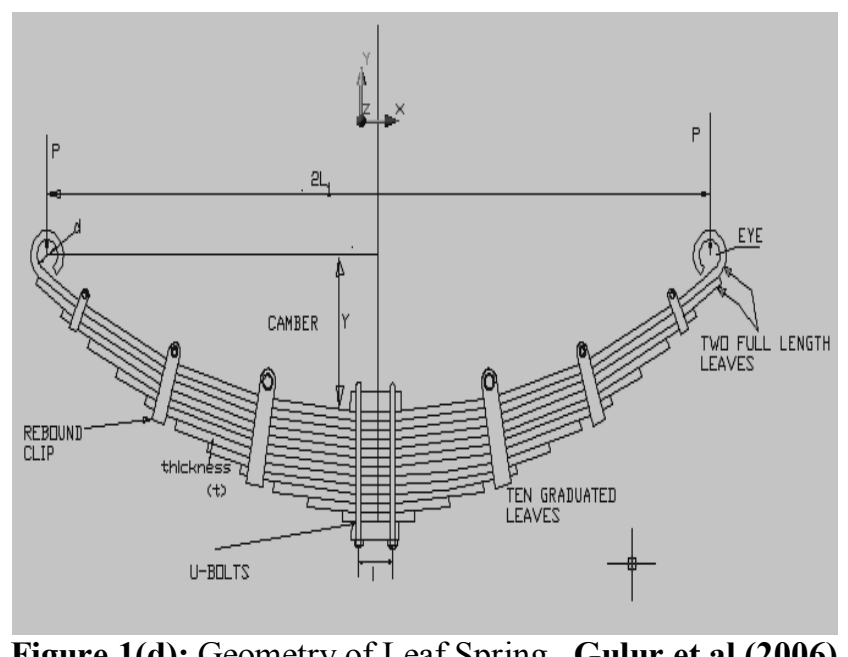

Figure 1(d): Geometry of Leaf Spring. Gulur et al (2006)

On a general note, spring function is evaluated according to the course and extent of its deformation depending on its load as express graphically in figure 2(c). 


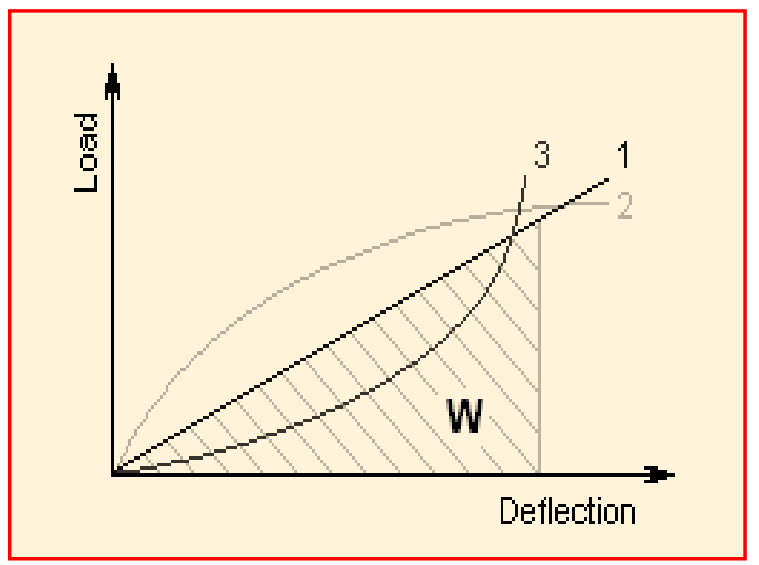

Figure1 (e): Spring deformation pattern.

Based on the deformation pattern, springs can be divided into the following three types:

1. springs with linear characteristics

2. springs with digressive characteristics

3. springs with progressive characteristics

The $\mathbf{W}$ area under the spring characteristic curve represents the deformation work (energy) of a spring performed by the spring during its loading.

Therefore, in justifying the material characteristic needed for the leaf spring, it should have high fatigue strength, high ductility, high resilience and it should be creep resistance (Khurmi, 2007). They are a good number of materials for leaf spring, but the material preferred in this report as will be justify using CES software is medium carbon steel having $0.4-0.7 \% \mathrm{C}$.

\section{Section 2:}

\section{1: Material selection using CES Software:}

Material selection is an important task in product development normally carried out by a design engineer (Sapuan, (2005). Depending on the design approach, material selection is carried out either in the earlier design stage for general material class selection and at the very advanced stage for specific materials. In this report, material selection was performed using the CES EduPack 2011 software to fine materials suitable for leaf spring. The parameters and values considered were:

Density $-100 \mathrm{~kg} / \mathrm{m}^{\wedge}$, Young Modulus $=200 \mathrm{Gpa}$, Fatigue strength=400Mpa, Fracture toughness $=15 \mathrm{Mpa} \cdot \mathrm{m}^{\wedge} 0.5$ and Yield strength $=750 \mathrm{Mpa}$.

Stage 1:- Limit selection:

A limit selection was conducted base on materials with high fatigue strength, high fracture toughness and high yield strength. Under this constrain, the CES software eliminated 98 materials and the possible materials for leaf spring were found to be:

- High carbon steel

- Medium carbon steel

- Low carbon steel

- Nickel

- $\quad$ Nickel base super alloys

- $\quad$ Stainless steel

- Tungsten alloy.

Stage 2:- Graph showing materials selected using CES EduPack software.

Comparison of fatigue strength/young modulus against density and fracture toughness/ density against price was further investigated and the result is shown on the graph in figure 2(a) and (b) below: 


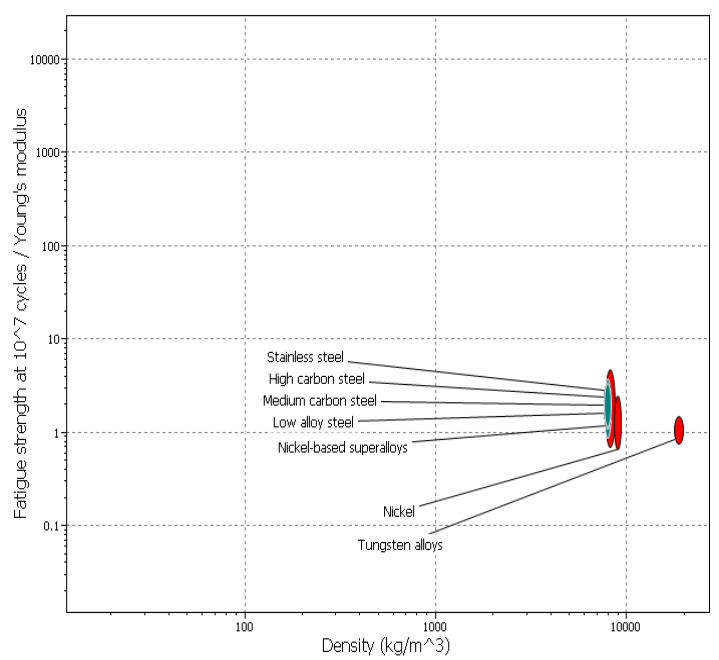

Figure 2(a): graph of fatigue strengh/young modulus against density.

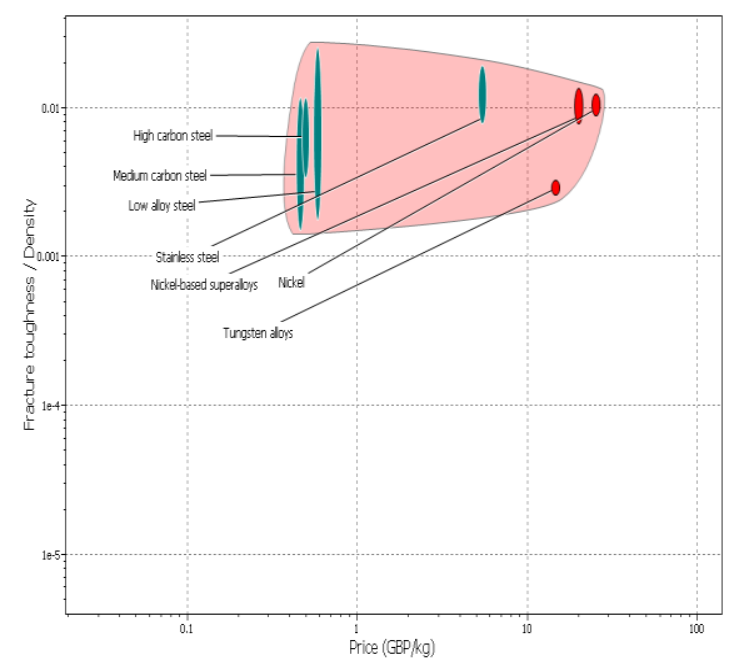

Figure 2(b): graph of fracture toughness/density against price.

\section{2: Material selection decision:}

From the investigation conducted, meduim carbon steel were found to be the best suitable material for the automotive leaf spring. While in terms of price, even though maintaning all it properties, meduim carbon steel is prefered as indicated in figure 2 (a) and (b) above respectively.

\section{3: Surface considerations:}

Fatigue: Fatigue failure is the predominant mode of in-service failure of many automobile components. This is due to the fact that the automobile components is under compression due to the weight of the vehicle and are subjected to corrosion (Ashby, 2011) and a variety of fatigue loads like shocks caused due to road irregularities traced by the road wheels, the sudden loads due to the wheel travelling over the bumps etc. The leaf springs are more affected due to fatigue loads, as they are a part of the unstrung mass of the automobile.

Friction: Mackerle, (1999) maintained that a leaf spring represents a contact problem with a sliding friction. The friction force opposes the sliding; therefore it acts on the leaves in one direction during loading and in the opposite direction during unloading. The loading and unloading paths result in a hysteresis. Leaf spring are interleaved or lubricated with Tsflon shims to make sliding easy (Ashby, 2011), also to take care of this situation, pad of low friction materials are often fix or put between the leaves to reduce this friction, also tight sealing of the springs is ensured to prevent entry of water or dirt (Birch, 1999);( Newton, 1996). Although in older vehicles, it is not easy to control interleaf friction and often causes a horrible ride.

Corrosion: The position of the leaf spring underneath the vehicle makes it easy for corrosion to occur because of the exposure to atmosphere, mud and water with acid content (Basshuysen, 2007). To prevent corrosion, all conventional leaf springs are smeared with grease on the tension side, excerpt the first leaf, and the spring are given a finishing coat of paint. 
Short penning: create a uniform layer of compressive stress at metal surfaces, shot peening provides considerable increases in part life. Compressive stresses are beneficial in increasing resistance to fatigue failures, corrosion fatigue, stress corrosion cracking, hydrogen assisted cracking, fretting, galling and erosion caused by cavitation. The maximum compressive residual stress produced just below the surface of a part by shot peening is at least as great as one-half the yield strength of the material being shot peened. A typical profile of residual compressive stress as it changes with depth is shown in Figure 2(c).
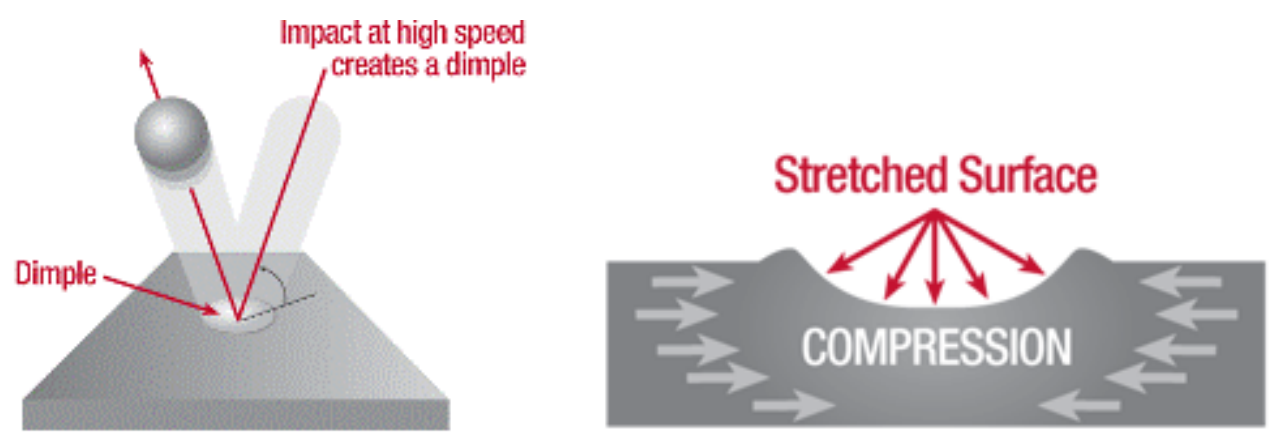

Fig.2(C) Example of Residual Stress Profile Created by Shot Peening. http://www.metalimprovement.com/shot_peening.php

\section{Section 3:}

\section{1: Choice of manufacturing route:}

The leaf spring manufacturing process will largely depends on the material selected. They choice of manufacturing route is influence through various method for processing the leave springs; Casting method, Machining method, Powder method and Roll-forging method (Yand Shenhua et al 1997). From the list the Roll-forging method of the leaf spring is of obvious advantages in saving in the investment in equipment, decreasing the consumption of material, enhancing productivity and ensuring product quality. The process leads to lower manufacturing cost with the same workpiece quality and becomes an economical and practical method for mass production.

\subsection{Justifying the current manufacturing route:}

Roll-forging has the advantage of enhancing productivity as well as ensuring quality product. The process is economical and can lead to mass production with lower cost. The leaves are heated in a furnace and pass on the taper rolling mill, where the leaves are then fed into a walking beam furnace to control the temperature.

On attaining the correct temperature, the spring leaves are place on a combined leaf spring cambering and hardening machine where the spring leaves are cambered to a predetermined curvature and simultaneously oil hardened by the rotation of the drum type cambering machine into the quenching oil bath. The spring leaves are then fed into a converyorise tempering furnace, passing through various temperatures to relieve the stresses developed due to oil hardening.

After tempering, the spring leaves are checked to ensure that they have attained the required hardness and tempered martensite structure. "Tempering requires heating the metal to a certain temperature and then cooling the metal at a carefully controlled rate. Cooling the metal too slowly might cause annealing. An annealed spring is soft and will bend or sag very easily. Cooling the spring too quickly might cause brittleness or hardening. An overly hard spring will snap because it will be too hard to bend" (Birch, 1999). Then the spring leaves are passed through a shot penning machine, which induces a residual compressive stress on the surface, thereby increasing the fatigue life of the spring. The spring assemblies are finally degreased, derusted and spray painted with anti-corrosive paint and baked in an oven to achieve the necessary anticorrosive properties.

Base on the above, the current manufacturing process scheme is show in figure 3(a) as follows: 


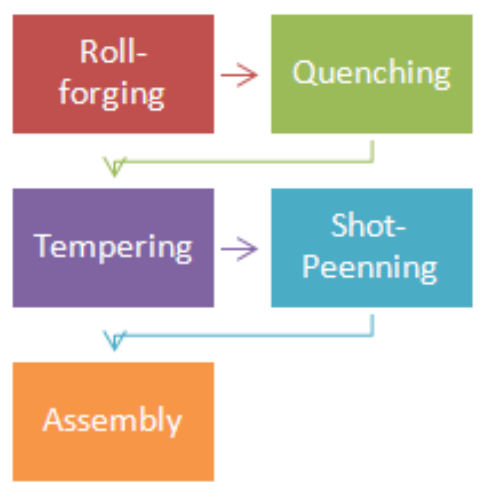

Figure 3(a): Manufacturing process for leaf spring.

\section{3: Impact of microstructural changes to the material:}

By this operation of hot forged, rapid quenching of a critical temperature, the grain structure of the spring leaf is transformed to martensite, which imparts the required hardness to the leaf. The impact of the steel shot produces microscopic plastic deformation on the surface. This will result to elongation at the surface layer. Since the bulk of the thickness remains underformed, this will prevent the elongation of the peened surface which in turn will cause compressive stresses at the surface.

Figure 3(b) shows the microstructure of the quench sample, after tempering the structure is of tempered martensite as shown in figure $3(\mathrm{c})$.

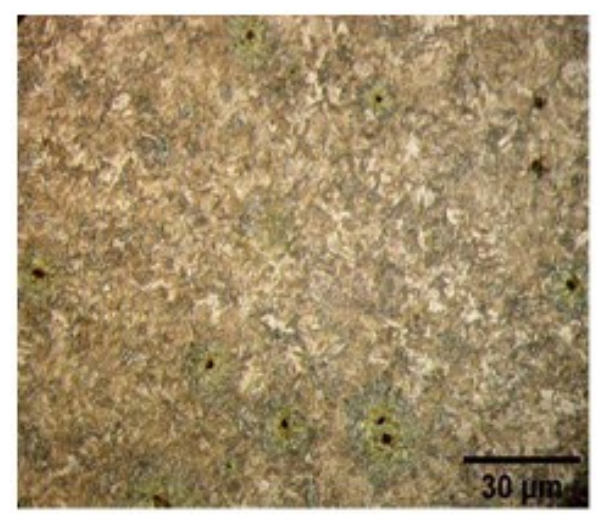

(b) As-quenched

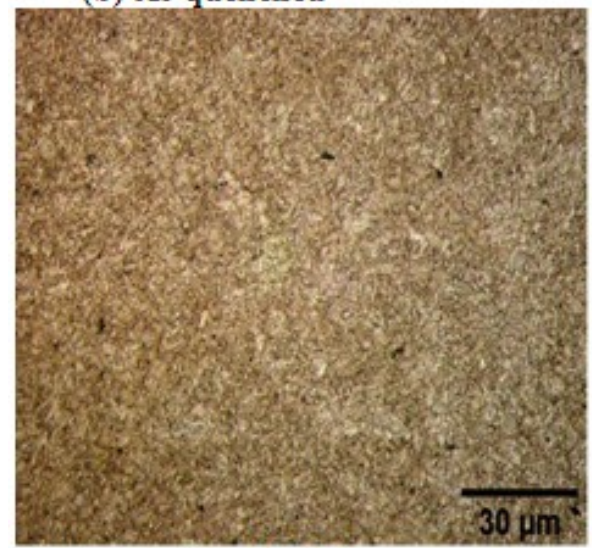

(c) Tempered at $400^{\circ} \mathrm{C}$

At this temperature of $400^{\circ} \mathrm{C}$, the prevalent martensite is an unstable structure and the carbon atoms diffuse from martensite to form a carbide precipitate and the concurrent formation of ferrite and cementite. This process allows microstructure modifications to reduce the hardness to the desire level while increasing the ductility. 


\section{Section 4:}

4.1: Alternate material(s) for leaf spring base on advanced selection using CES software:

In order to conserve natural resources and economize energy, weight reduction has been the main focus of automobile manufacturer in the present state. Weight reduction can be achieved primarily by the introduction of better material, design optimization and better manufacturing processes. The suspension leaf spring is one of the potential items for weight reduction in automobile as it accounts for ten to twenty percent of the unsprung weight. This helps in achieving the vehicle with improved riding qualities. It is well known that springs, are designed to absorb and store energy and then release it (Shiva Shanka and Vijayarangan 2006).

In selecting a suitable advance material that will be of light weight, cost effective and better service efficiency, selection was performed using the CES EduPack 2011 software using the following parameters: Density-100 kg/m ${ }^{\wedge}$, Young Modulus=20Gpa, Fatigue strength=70Mpa, Fracture toughness $=15 \mathrm{Mpa} . \mathrm{m}^{\wedge} 0.5$ and Yield strength=50Mpa. From the 98 material screens, the material selected among others is indicated in the graph bellows follows:

- GFRP, epoxy matrix (isotropic)

- CFRP, epoxy matrix (isotropic)

- Cast magnesium alloy

- Aluminium/silicon carbide composite etc.

\section{2: Material selection decision:}

From the investigation conducted, GFRP were found to be the best suitable advanced material for the automotive leaf spring maintaining good advantage over others. While in terms of price, even though maintaning all it properties, GFRP is relatively low cost as indicated in figure 4 (a) and (b) respectively.

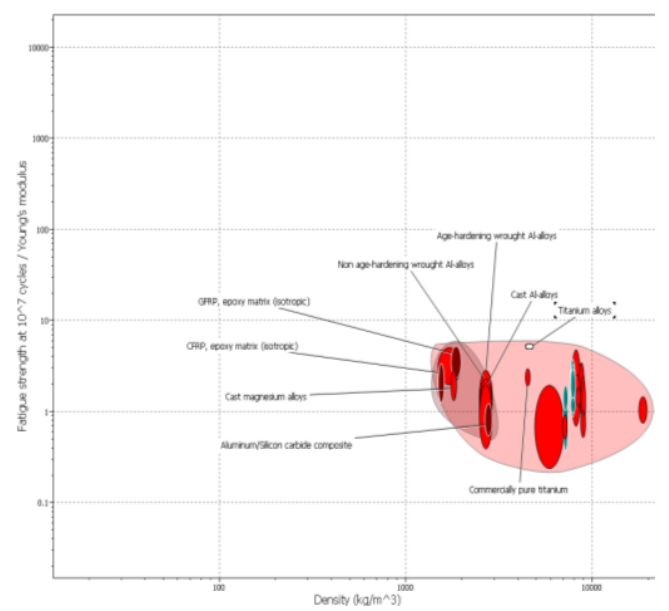

Figure 4(a): graph of fatigue strength/young modulus against density

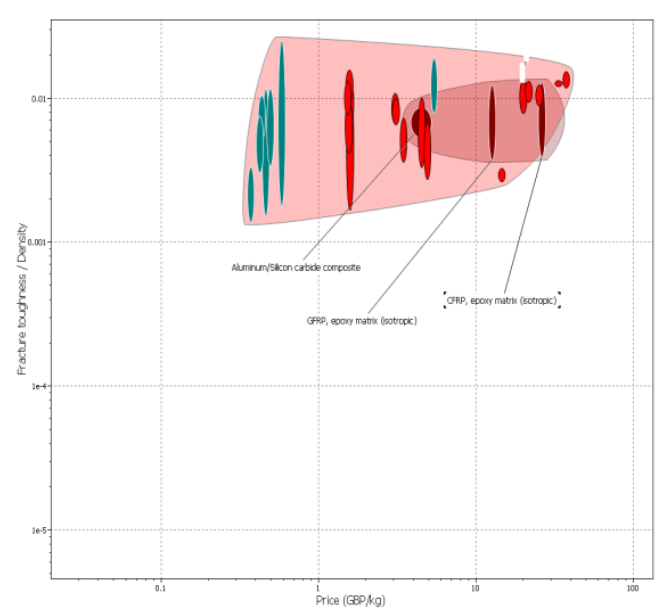

Figure 4(b): graph of fracture toughness/density against price. 


\section{3: Advantage and Limitations:}

\section{Advantage:}

i. Low E- modulus approximately to be 7-times lower in comparison with the steel, together with internal damping and low dynamic stiffness in comparison with static stiffness, makes GFRP composite suitable for the manufacturing of road friendly leaf spring and suspension.

ii. Low specific weigth- it has been agured that a $60 \%$ reduction of the whole suspension weight can be obtained by replacing steel spring with GFRP springs with the same functions. This is particularly important because springs represent unsprung mass.

iii. It has the advantage of using just one or two leaves with stable damping properties and other characteristics during the whole service life.

iv. An efficient noise damping is an additional, but most important of the GFRP material is making suspension more environmentally friendly.

v. Have high strength

vi. Have excellent fatigue resistance.

vii. Free from corrosion

All these advantages are the reason, why the design and characterisation of glass fibre reinforced composites have received recently a great amount of interest (Harris 1990; Chaplin, Mayer and Rezakhanlou 1995; Chianumba, Jeronimidis and Mayer 1997).

\section{Limitations.}

i. Any change of shape and size of a component can affect its mechanical properties due to the material hetrogenity.

ii. If the process parameters are not correctly or other characteristics of the constituents like glass performs are not perfectly maintained or incorrectly selected, various kind of defect can arise, like bubbles, voids, porosity or insufficient wetting.

iii. Defect have the ability to reduced static and fatigue strength

(Stone and Clarke 1974; Rheiländer, Nielsen, Borum and Gundtoft 1997)

\section{Section 5}

\section{1: Justifying a manufacturing route for the advance material:}

(a): Pultrusion: Pultrusion is a process for making composite parts on a continuous basis. Studies have shown that pultrusion is the lowest cost process for making advanced composite parts, that is, the types of products used in automobile aircraft where fibre placement and part performance are a premium (Fanucci 1992, Krolewski 1986). These data assert that pultrusion costs are only $41 \%$ as much as filament winding and only $26 \%$ as much as prepreg hand layup. A schematic of the pultrusion process is presented in Fig 5(a). The pultrusion process involves a few simple, but vital components, which include: fibre reinforcement, resin impregnation tank, preform plate system, heated die, puller, and cut-off saw.

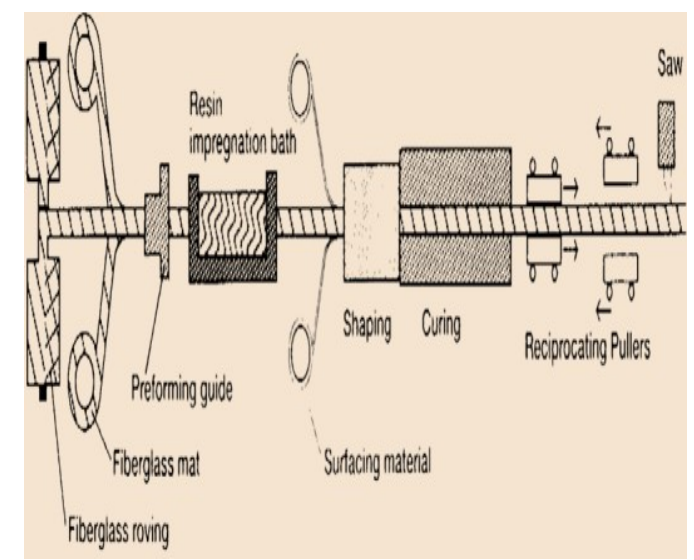

Figure 5(a): A typical Pultrusion process (van de velde et al 2001)

Goldsworthy(1991) report that pultrusion is becoming much more versatile and offers some advantages for a wide variety of parts, some of which cannot be economically made with other processes. Parts currently made using pultrusion include the following: automobile leaf springs, automotive transport train cars, aircraft components, trailer structural beams, trim parts, ship/submarine components, and monorail structural and decorative components etc. 
In the manufacturing of the leaf spring through this process, it required some innovation to allow parts of non-constant cross-section to be made, and this innovation is referred to as pulforming. Automotive leaf springs are produced by pulforming. Each of the moulds is the shape of the completed leaf spring - narrow and thick on the ends, wide and thin in the middle, and curved overall. The moulds are mounted on a moving belt that goes around a curved frame which exactly matches the curve of the dies. Hence, the parts are simultaneously gripped and pulled by the dies and the belt, pressed into the moulds, forced around a curve, and cured. A cut-off device, mounted at the exit point of the curved forming frame, separates the leaf springs at appropriate sites between the moulded portions. Figure (5b) shows a prepared specimen of composite leaf spring.

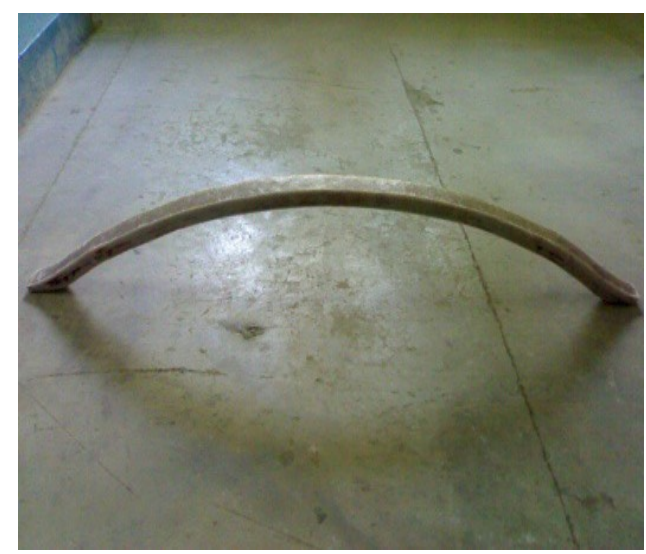

Figure 5(b) Specimen of composite leaf spring. (K. K. Jadhao et al 2011)

(b): Prepreg: Vacuum bag and autoclave processing are the two main methods for manufacturing components from prepreg.

The vacuum bag technique involves the placing and sealing of a flexible bag over a composite lay-up and evacuating all the air from under the bag. The removal of air forces the bag down onto the lay-up with a consolidation pressure of 1 atmosphere ( 1 bar). The completed assembly, with vacuum still applied, is placed inside an oven with good air circulation, and the composite is produced after a relatively short cure cycle.

The autoclave technique requires a similar vacuum bag but the oven is replaced by an autoclave. The autoclave is a pressure vessel which provides the curing conditions for the composite where the application of vacuum, pressure, heat up rate and cure temperature are controlled. High processing pressures allow the moulding of thicker sections of complex shapes. Honeycomb sandwich structures can also be made to a high standard. Long cure cycles are required because the large autoclave mass takes a long time to heat up and cool down. Sometimes slow heat up rates are required to guarantee even temperature distribution on the tooling and composite components.

\section{Conclusion:}

The movement from the normal conventional material for leaf spring to the development of an alternative composite leaf spring having constant cross sectional area, where the stress level at any station in the leaf spring is considered constant due to the parabolic type of the thickness of the spring, has proved to be very effective.

The research demonstrated that composites can be used for leaf springs for light weight vehicles and meet the requirements, together with substantial weight savings.

The selection decision of both steel and composite leaf spring is done and analysed using Cambridge educational software CES EduPark 2013.

A comparative study has been made between composite and steel leaf spring with respect to weight, cost and strength. From the results, it is observed that the composite leaf spring is lighter and more economical than the conventional steel spring with similar design specifications.

Composite leaf spring reduces the weight by $85 \%$ for E-Glass/Epoxy, over conventional leaf spring.

\section{References:}

[1]. AL-Qureshi., H. A (2001) Automotive Leaf Spring from Composite Material. Journal of Materials Processing Technology Vol.118 pp 56-61[online] available from $<$ http//www.sciencedirect.com $>$ access on [25/7/2012]

[2]. Ashby, M., (2011) Material Selection in Mechanical Design. $4^{\text {th }}$ ed. Butterworth- Heinemann.

[3]. Basshuysen, R. Schafer, F (2007) Modern Technology from A to Z. $1^{\text {st }}$ end SAE International.

[4]. Chaplin, C.R., Mayer, R.M. and Rezakhanlou, R. (1995). A new approach to composite leaf springs. In: Proc. of the Autotech conference, Birmingham, Ed. I Mech Eng, London. 
[5]. Chianumba, A., Jeronimidis, G. and Mayer, R.M. (1997). Advanced vehicle suspensions using glass reinforced plastics. In: Proc. of the 6th European Congress on Lightweight and Small Cars: The Answer to Future Needs, Cernobbio, Italy; 549-558.

[6]. Erjavec, J. (2012) Automotive Technology: A system approach. $5^{\text {th }}$ edn. Delmar, Cengage Learning.

[7]. Fanucci, Jerome P. 1992. Something Different in Pultrusion, Presented at Effective Methods of Pultrusion Technology Clinic, Dearborn, MI: SME.

[8]. Goldsworthy, Brandt. 1991. Pultrusion. Vol. 6 of International Encyclopaedia of Composites, edited by Stuart Lee. New York: VCH Publishers, Inc.

[9]. Harris, LR. (1990). Composite leaf spring design. GKM Technology report.

[10]. Heisler, H., (1999) Vehicle and Engine Technology. 2 edn. Arnold Publishers.

[11]. http://www.mitcalc.com/doc/springs/help/en/springstxt.htm.

[12]. http://www.tech.plymouth.ac.uk/sme/desnotes/fatiguecalc.htm

[13]. Hiroyuki Sugiyama et al (2006).Development of nonlinear elastic leaf spring model for multibody vehicle systems. Computer Methods in Applied Mechanics and Engineering, Volume 195, Issues 50-51, 15 October 2006, Pages 6925-6941[online] available from $<$ http//www.sciencedirect.com $>$ [5 $5^{\text {th }}$ July 2012].

[14]. Htun, M., Kyaw, S., Lwin, K., (2009).Effect of Heat Treatment on Microstructures and Mechanical Properties of Spring Steel. Journal of Metals, Materials and Minerals, Vol.18 No.2 pp.191-197.

[15]. Indian Leaf Spring Mfg.Co.Pvt, Hyderabad, India. [Online] available from $<\quad$ http.www.indialeaf.com $>$

[16]. Jaroslav Mackerle, (1999),"Finite element analysis of machine elements: A bibliography (1977-1997)", Engineering Computations, Vol. 16 Iss: 6 pp. $677-748$

[17]. K. K. Jadhao et al. (2011) Experimental investigation \& numerical analysis of composite leaf spring. International Journal of Engineering Science and Technology (IJEST) Vol. 3 No. 6 June 2011 [online] available from http://www.ijest.info/docs/IJEST1103-06-127.pdf access on [6/8/2012].

[18]. Khurmi, R., Gupta, J (2007) A Textbook of Machine Design $1^{\text {st }}$ edn. Eurasia Publishing House (PVT.) Ltd.

[19]. Krolewski, Susan and Timothy Gutowski (1986). Effect of the Automation of Advanced Composite Fabrication Process on Part Cost. SAMPE Quarterly, October, 43.

[20]. Mahmood M. Shokrieh, Davood Rezaei (2003) Analysis and optimization of a composite leaf spring. Vol. 60 pp. $317-325$. [Online Elsevier] available from $<$ www.sciencedirec.com $>$ access on [20/6/2012]

[21]. Mukhopadpyay, M.K. et al (1997) 'Premature failure of leaf a spring due to improper material processing'. Engineering Value Analysis.Vol.4.No.3, pp161-170 [online] available from $<$ http//www.sciencedirect.com $>\left[10^{\text {th }} \mathrm{July}, 2012\right]$.

[22]. M.venkatesan., D.helmen devaraj (2012) Design and Analysis of Composite Leaf Spring in Light Vehicle. International Journal of Modern Engineering Research (IJMER) www.ijmer.com Vol.2, Issue.1, Jan-Feb 2012 pp-213-218ＩSSN: 2249-6645 www.ijmer.com 213 .

[23]. Nunny, M.J. (2007) Light and Heavy Vehicle Technology.4 edn. Elservier Ltd

[24]. Rheiländer, J.T., Nielsen, S.A., Borum, K.K. and Gundtoft, H.E. (1997). NDE of polymeric composites: A comparison of techniques. In: Proc of the 18th Risoe Int. Symposium on Materials Science, Eds. Andersen S.I. et. al., Risø National Laboratory, Roskilde, Denmark, 1997, 101-125.

[25]. Sapuan., M (2005),"Concurrent design and manufacturing process of automotive composite components", Assembly Automation, Vol. 25 Iss: 2 pp. $146-152$.

[26]. Shiva Shankar, G., Vijayarangan, S. (2006) Mono Composite Leaf Spring for Light Weight Vehicle- Design, End Joint Analysis and Testing. Material Science (Medziagotyra) Vol. 12, No. 3 ISSN 1392.1320[online] available from < http//www.sciencedirect.com $>\left[10^{\text {th }}\right.$ July, 2012].

[27]. Stone, D.E.W. and Clarke, B. (1974). Non-destructive determination of the void content in carbon fibre reinforced plastics by measurement of ultrasonic attenuation. RAE Tech. Report 74172.

[28]. Yang Shenhua, Kou Shuqing, Deng Chunping (1997) Research and application of precision roll-forging taper-leaf spring of vehicle. Journal of Materials Processing Technology Vol. 65 (1997) pp. 268-271. 